\title{
Cerebral venous sinus thrombosis in infant with COVID-19
}

\author{
Jana Blazkova ${ }^{1} \cdot$ Petr Skalicky $^{1,2} \cdot$ Ondrej Bradac $^{1,2}\left(\right.$ O Vladimir Benes Jr. $^{1}$ \\ Received: 23 August 2021 / Accepted: 6 January 2022 / Published online: 19 January 2022 \\ (c) The Author(s), under exclusive licence to Springer-Verlag GmbH Austria, part of Springer Nature 2022
}

\begin{abstract}
We present a rare case of cerebral venous sinus thrombosis in a COVID-19-positive, 2-month-old infant, to this day the youngest described patient with this rare combination of findings. He was hospitalized with focal seizures. The first brain imaging showed subdural hematoma and focal ischemic changes. The subdural hematoma was successfully evacuated. The control imaging, done due to lethargy, showed an extensive cerebral venous sinus thrombosis. The thrombosis was managed with low molecular weight heparin leading to clinical and radiological improvement. With this case report, we would like to add to the information pool of COVID-19 neurological manifestations in children, particularly those younger than 1 year.
\end{abstract}

Keywords Case report · Cerebral venous sinus thrombosis · COVID-19 · Infant

$\begin{array}{ll}\begin{array}{l}\text { Abbreviations } \\ \text { SARS-CoV-2 }\end{array} & \begin{array}{l}\text { Severe acute respiratory syndrome corona- } \\ \text { virus } 2\end{array} \\ \text { COVID-19 } & \begin{array}{l}\text { Coronavirus disease } 19 \\ \text { Magnetic resonance imaging }\end{array} \\ \text { MRI } & \text { Subdural hematoma } \\ \text { SDH } & \text { Low molecular weight heparin } \\ \text { LMWH } & \text { Venous sinus thrombosis } \\ \text { CVT } & \text { Angiotensin-converting enzyme 2 } \\ \text { ACE2 } & \end{array}$

\section{Introduction}

Severe acute respiratory syndrome coronavirus 2 (SARSCoV-2) is known to be a dangerous virus affecting not only the respiratory tract but also other organs by several mechanisms. There are increasing reports of cerebrovascular complications, both ischemic and hemorrhagic. While the coronavirus disease 2019 (COVID-19)-induced neurological

This article is part of the Topical Collection on Pediatric Neurosurgery

Ondrej Bradac

Ondrej.Bradac2@fnmotol.cz

1 Department of Neurosurgery, 2nd Faculty of Medicine, Charles University in Prague and Motol University Hospital, V Uvalu 84, Prague 15600, Czech Republic

2 Department of Neurosurgery and Neurooncology, 1st Faculty of Medicine, Charles University in Prague and Military University Hospital, Prague, Czech Republic symptomatology in the adult population is well described and documented [10-13, 16, 17], the same information about neurological manifestation in the youngest patients — newborns and infants - is almost nonexistent.

We present a case of an 8-week-old infant admitted for several epilepsy-like seizures and magnetic resonance imaging (MRI) findings of subdural hematoma (SDH) and focal ischemic changes of brain parenchyma. With this case report, we would like to shed more light and attention on the COVID-19 neurological complications in pediatric patients. These may be overlooked as children with COVID-19 are often asymptomatic or present with unusual respiratory symptomatology. Thus neurological symptoms are not always thought to be caused by the SARS-CoV-2 which may lead to a delay in diagnosis and treatment.

\section{Case presentation}

The boy was born full-term, spontaneously. His parents and attending pediatrician had not observed any developmental or behavioral abnormalities until the COVID-19 infection.

In the 7th week of life, he presented with a fever as the first sign of COVID-19 infection. After 4 days, fever subsided, and he and his whole family were tested positive in nasopharyngeal swabs examined by polymerase chain reaction method. On the same day as tested, he manifested first neurological symptoms, consisting of right-sided facial muscle spasms and left upper limb spasm. He was hospitalized at a Pediatrics Department of his regional hospital. 
The next day, the frequency of seizures - uniform with those presented the day before - increased to ten in 1 day. In response, the valproate therapy was commenced and an electroencephalography was performed showing abnormality of the right temporal lobe. MRI (Fig. 1) discovered early development of SDH (maximal diameter $5 \mathrm{~mm}$ ) along the right cerebral hemisphere, as well as a slight compression of the right lateral ventricle and midline shift of $3 \mathrm{~mm}$, early development of ischemia in the temporo-parieto-occipital parenchyma of the right hemisphere with uncertain etiology.

The following day, he was transferred to our clinic for evacuation of the SDH; external subdural drainage was placed without complications. After 2 weeks of improvement of the overall status, the patient became lethargic and required longer sleep than usual. Thus, an MRI (Fig. 2) was performed and showed regression of subdural collection, usual development of postischemic changes, unexpected development of bilateral thrombosis of transverse sinuses reaching to sigmoid sinuses, confluens sinuum, and sagittal superior sinus. Anticoagulation therapy was started immediately, the dosage of low molecular weight heparin (LMWH) was adjusted according to antiXa therapeutic levels.
Family history was unremarkable for autoimmune diseases or genetic prothrombotic conditions. No prothrombotic abnormalities were found in blood tests, with normal levels of protein $\mathrm{C}$ and $\mathrm{S}$, antithrombin III, and anti-Xa. In genetic testing, a homozygous mutation of MTHFR $677 \mathrm{C}>\mathrm{T}$ was confirmed, and mutations for factor V Leiden and factor II Prothrombin 20210A were negative.

After 2 weeks of anticoagulation therapy, a control MRI (Fig. 3) was performed, showing significant improvement of the venous sinus thrombosis (CVT) with remaining thrombotic residues, however with renewed flows in all sinuses. The postischemic changes of the right temporoparieto-occipital parenchyma showed usual development with the regression of perifocal edema. The LMWH therapy was continued for a total of 52 days, when MRI showed minimal residual thrombosis. On the neurological examination performed at the age of 3 months, light central hypotonia was present; he fixated well, smiled, moved his head freely, and when lying on his stomach, pushed up to elbows.
Fig. 1 MRI from the day of admission showing SDH and ischemia. A MRI axial diffusion shows the ischemia of temporoparieto-occipital parenchyma of the right hemisphere; B MRI axial flair shows the subdural hematoma surrounding the right hemisphere; C MRI T2W enhancement of the walls of the sagittal sinus, showing a probable inflammation; D MRI axial diffusion without any signs of thrombosis yet

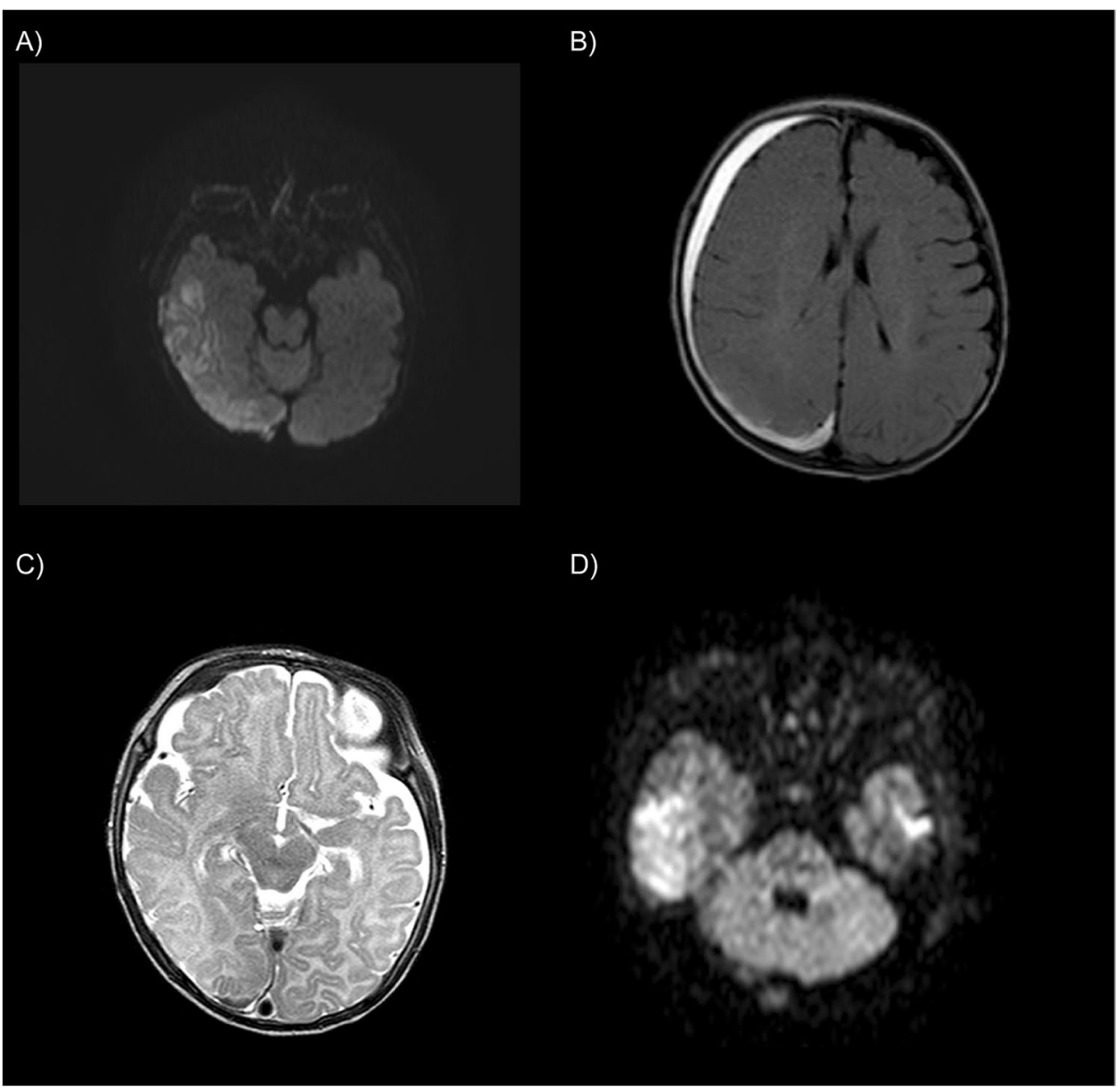


Fig. 2 MRI done in 2 weeks of the evacuation of the SDH showing CVT. A MRI T1 sag shows the thrombosis of the sagittal sinus and confluens sinuum; B MR diffusion shows the thrombosis invading further into both transverse sinuses; $\mathbf{C}$ MRI T2 axial demonstrates the progression of left hemisphere ischemia; D MRI T1W shows the thrombosis of the transverse sinuses

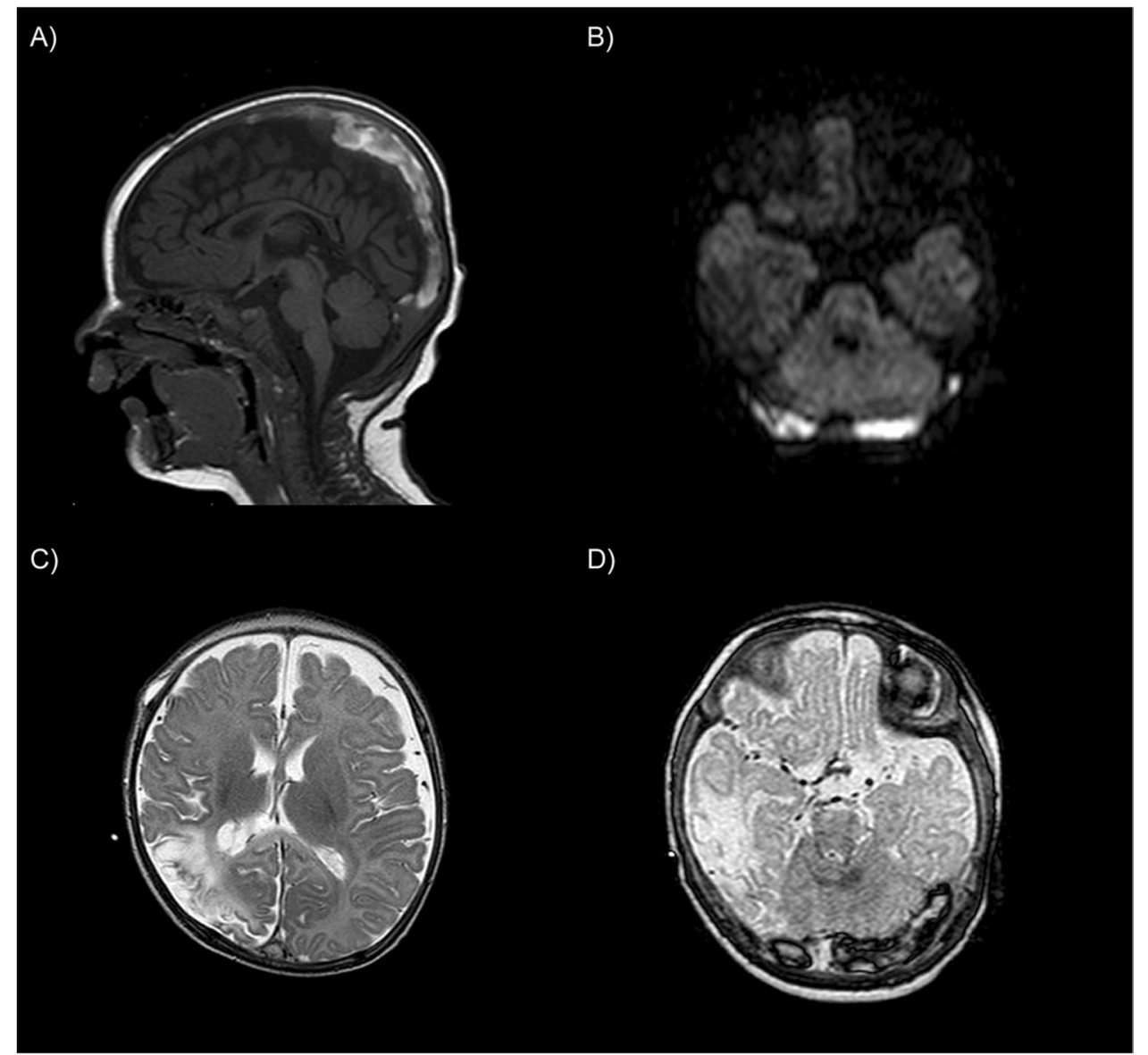

\section{Discussion}

The youngest patient with COVID-19-induced CVT, described to this date - to the best of our knowledge - is a 2-year 7-month-old girl. However, this girl suffered from both COVID-19 and tuberculous meningitis coinfection [8]. Her findings slightly differed, as her computer tomography scan showed pan-hydrocephalus and basal meningeal enhancement, not present in our patient.

SARS-CoV-2 causes various neurological complications by several mechanisms; it enters cells through the angiotensin-converting enzyme 2 (ACE2) receptor. Various cells express these receptors, such as those of the respiratory tract, endothelial cells, arterial smooth muscle cells, glial cells, and neurons, which renders them potential targets for the virus $[10,11,20]$. Due to the involvement of neurons and cerebral vasculature, cerebrovascular complications are not uncommon [10,11, 13, 17, 20]. When ACE2 receptors are occupied by the virus, they get inactive, causing dysregulation of blood pressure, as they hold an important role in cerebrovascular autoregulation and blood flow [14]. The dysregulation of the system causes hypertensive peaks and endothelial pathology, which adds to the pathogenesis of both ischemic and hemorrhagic stroke. Additionally, the inactive receptors lead naturally to the accumulation of angiotensin 2 , which results in a postischemic inflammation cascade. As a consequence, the borderline parts of the ischemic zone lose the remaining perfusion and the infarct volume develops further $[12,16]$.

Another pathophysiologic pathway of COVID-19 is its ability to induce a cytokine storm in the host organism, leading to a cascade of inflammatory reactions, causing coagulation system failure $[5,12,16]$. All of the mentioned mechanisms add to the pathophysiology of COVID-19-induced ischemic strokes and CVT $[12,16]$.

Children constitute less than $2 \%$ of COVID-19-positive patients and less than $20 \%$ of them are children under 1 year of age $[7,15]$. However, this age group manifests more severe clinical presentation in contrast to the rest of the pediatric population with the usually mild course of the disease. The most common symptoms seen in COVID-19-positive infants are fever, cough, shortness of breath, cyanosis, feeding intolerance, vomiting, and diarrhea $[7,15]$. The main symptomatology being nonspecific collides with the presentation of even rarer cerebral venous sinus thrombosis in infants which affects less than 1/100,000 children annually. Etiology commonly includes dehydration, infection, sepsis, severe anemia, head trauma, and coagulopathies. Clinical 
Fig. 3 The control MRI, done within the 2 weeks of the previous imaging showing regression of the CVT. A MRI T1 sag demonstrates the reduction of the thrombosis of the sagittal sinus; B MRangio shows the renewed flow in the cerebral venous sinuses system; $\mathbf{C}$ MRI T2 axial shows the usual development of left hemisphere ischemia; D MRI T1W demonstrates the diminution of the thrombosis of the transverse sinuses

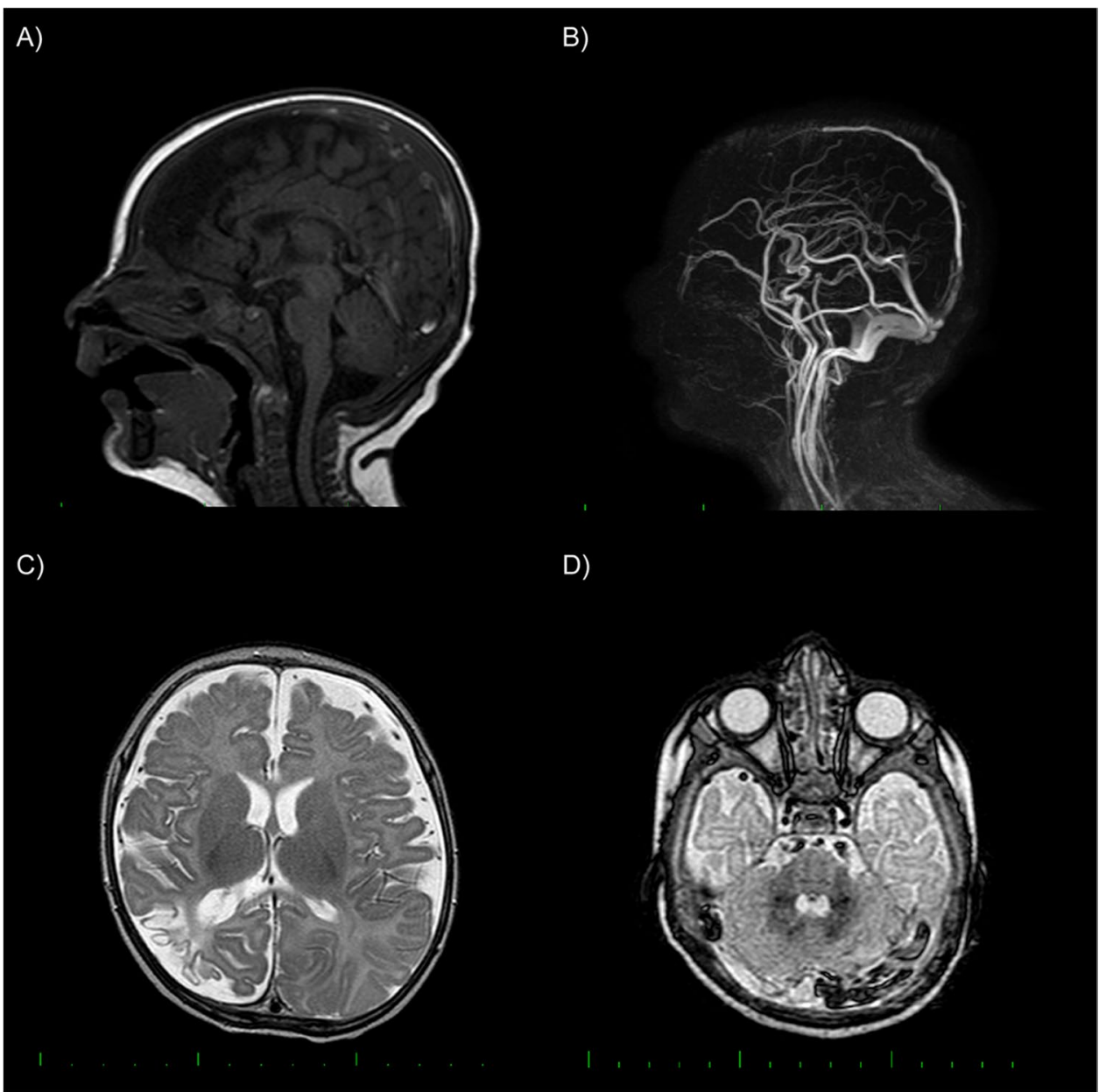

presentation is also nonspecific, with fever, irritability, seizures, vomiting, and altered consciousness as predominant symptoms in infants $[2,3,9,18]$.

Our patient suffered from cerebrovascular pathologies of hemorrhagic and ischemic etiologies. The first to appear, SDH, was captured in an early state on the first MRI imaging, which was done 6 days after the onset of COVID-related symptomatology. The second cerebrovascular pathology was the parenchymal ischemia which also showed a recent appearance on the first MRI, as both of those pathologies showed restriction of diffusion. The CVT was discovered 3 weeks after the disease onset, and among described patients, it is a rather late appearance. However, the first radiologic marks were present on the initial MRI, even though described only retrospectively. After a closer inspection, an inflammation of the sinus walls can be recognized as well as a deceleration of the blood flow velocity.

One of the possible etiologies of the SDH in infants could be external hydrocephalus, which causes the bleeding by the expansion of the subarachnoid space - stretching the bridging veins. This could lead to spontaneous bleedings or bleedings following minor trauma [1]. The increased sinocortical width, craniocortical width, and interhemispheric distance present at the MRI controls (Figs. 2C and 3C) could also point out to this diagnosis. Nevertheless, our patient did not show any signs of this condition prior to the COVID-19 onset, notably his head circumference followed the median for his age (Fig. 4), rendering this possible etiology rather improbable [1, 19].

There were several abnormalities in the coagulation tests. Some coagulation factors, even though in an acceptable range, were of marginal values, most likely as the result of prolonged vascular pathologies. The mutation of MTHFR $677 \mathrm{C}>\mathrm{T}$, although present, should not be solely responsible for such a dramatic course either $[4,6]$. It is likely that the combination of this predisposition, triggered by the infection, led to the unusual picture observed.

The anticoagulation therapy was adjusted repeatedly in order to reach desired therapeutic levels and was ultimately successful. Despite conflicting pathology (SDH), no new hemorrhage occurred due to sufficient time between drainage and start of CVT treatment; in this respect, the delay in CVT diagnosis proved fortuitous since it allowed sufficient treatment of the SDH in the meantime. 
Fig. 4 The graph compares the head growth of our patient with the population median and shows that the head circumference of our patient did not record any sudden increase and did not deviate much from the normal distribution in the population, antagonizing the possible etiology of the external hydrocephalus

\section{Head circumference}

- Normal development (median) - Our patient

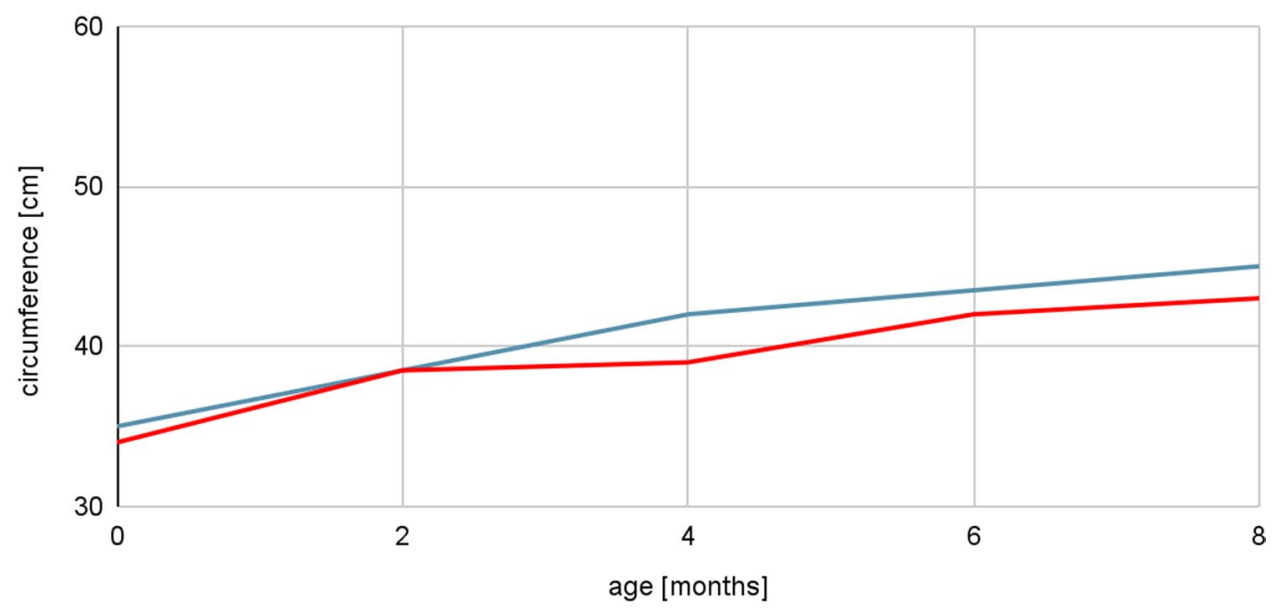

\section{Conclusion}

Cerebrovascular complications in COVID-19-positive infants can occur, however rarely. The delay in diagnosis and treatment can be caused by nonspecific symptomatology and possible misinterpretation of radiologic images. As in our case, the possible warnings of the forthcoming CVT could have been recognized at the first MRI, despite their discreet appearance. COVID-19-positive infants with nonspecific symptomatology should always raise suspicion for possible cerebrovascular complications and the imaging methods should be indicated and read carefully.

Author contribution Jana Blazkova, MD, drafted the initial manuscript and reviewed and revised the manuscript. Petr Skalicky, MD, reviewed and revised the manuscript. Assoc. prof. Ondrej Bradac, MD, MSc, $\mathrm{PhD}$, conceptualized and designed the study and reviewed the manuscript. Assoc. prof. Vladimir Benes, $\mathrm{MD}, \mathrm{PhD}$, revised and critically reviewed the manuscript for important intellectual content. All authors approved the final manuscript as submitted and agreed to be accountable for all aspects of the work.

Availability of data and material Not applicable.

Code availability Not applicable.

\section{Declarations}

Conflict of interest The authors declare no competing interests.

\section{References}

1. Andersson J, Wikström J, Högberg U, Wester K, Thiblin I (2021) External hydrocephalus as a cause of infant subdural hematoma: epidemiological and radiological investigations of infants suspected of being abused. Pediatr Neurol 126:26-34

2. Barnes C, Newall F, Furmedge J, Mackay M, Monagle P (2004) Cerebral sinus venous thrombosis in children. J Paediatr Child Health 40(1-2):53-55

3. Beri S, Khan A, Hussain N, Gosalakkal J (2012) Severe anemia causing cerebral venous sinus thrombosis in an infant. J Pediatr Neurosci 7(1):30-32

4. Bezemer ID, Doggen CJ, Vos HL, Rosendaal FR (2007) No association between the common MTHFR 677C-> T polymorphism and venous thrombosis: results from the MEGA study. Arch Intern Med 167(5):497-501

5. Dakay K, Cooper J, Bloomfield J, Overby P, Mayer SA, Nuoman $\mathrm{R}$ et al (2021) Cerebral venous sinus thrombosis in COVID-19 infection: a case series and review of the literature. J Stroke Cerebrovasc Dis. 30(1): 105434

6. Dean L (2012) Methylenetetrahydrofolate reductase deficiency. In: Pratt VM, Scott SA, Pirmohamed M, Esquivel B, Kane MS, Kattman BL et al (eds) Medical Genetics Summaries. Bethesda, MD

7. De Rose DU, Piersigilli F, Ronchetti MP, Santisi A, Bersani I, Dotta A et al (2020) Novel coronavirus disease (COVID-19) in newborns and infants: what we know so far. Ital J Pediatr 46(1):56

8. Essajee F, Solomons R, Goussard P, Van Toorn R. Child with tuberculous meningitis and COVID-19 coinfection complicated by extensive cerebral sinus venous thrombosis. BMJ Case Rep. 2020;13(9).

9. Jani S, Ariss R, Velumula P, Altinok D, Chawla S (2020) Term infant with cerebral venous sinus thrombosis. Case Rep Pediatr 2020:8883007 
10. Li Y, Li M, Wang M, Zhou Y, Chang J, Xian Y et al (2020) Acute cerebrovascular disease following COVID-19: a single center, retrospective, observational study. Stroke Vasc Neurol 5(3):279-284

11. Mao L, Jin H, Wang M, Hu Y, Chen S, He Q et al (2020) Neurologic manifestations of hospitalized patients with coronavirus disease 2019 in Wuhan China. JAMA Neurol 77(6):683-690

12. Mowla A, Shakibajahromi B, Shahjouei S, Borhani-Haghighi A, Rahimian N, Baharvahdat $\mathrm{H}$ et al (2020) Cerebral venous sinus thrombosis associated with SARS-CoV-2; a multinational case series. J Neurol Sci. 419:117183

13. Sweid A, Hammoud B, Bekelis K, Missios S, Tjoumakaris SI, Gooch MR et al (2020) Cerebral ischemic and hemorrhagic complications of coronavirus disease 2019. Int J Stroke 15(7):733-742

14. Tabibkhooei A, Hatam J, Mokhtari M, Abolmaali M (2021) COVID-19-associated spontaneous subacute subdural haematoma: report of two cases. New Microbes New Infect. 40:100848

15. Tezer H, Bedir Demirdag $T$ (2020) Novel coronavirus disease (COVID-19) in children. Turk J Med Sci. 50(SI-1):592-603

16. Tsivgoulis G, Palaiodimou L, Zand R, Lioutas VA, Krogias C, Katsanos AH et al (2020) COVID-19 and cerebrovascular diseases: a comprehensive overview. Ther Adv Neurol Disord 13:1756286420978004
17. Valiuddin HM, Kalajdzic A, Rosati J, Boehm K, Hill D (2020) Update on neurological manifestations of SARS-CoV-2. West J Emerg Med 21(6):45-51

18. Wasay M, Dai AI, Ansari M, Shaikh Z, Roach ES (2008) Cerebral venous sinus thrombosis in children: a multicenter cohort from the United States. J Child Neurol 23(1):26-31

19. Zahl SM, Egge A, Helseth E, Wester K (2011) Benign external hydrocephalus: a review, with emphasis on management. Neurosurg Rev 34(4):417-432

20. Zhou Z, Kang H, Li S, Zhao X (2020) Understanding the neurotropic characteristics of SARS-CoV-2: from neurological manifestations of COVID-19 to potential neurotropic mechanisms. J Neurol 267(8):2179-2184

Publisher's note Springer Nature remains neutral with regard to jurisdictional claims in published maps and institutional affiliations. 